Synthesis, part of a Special Feature on The Conservation and Restoration of Old Growth in Frequent-fire Forests of the American West

\title{
Monitoring Old Growth in Frequent-fire Landscapes
}

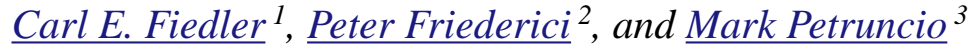

\begin{abstract}
In this article, we discuss how to monitor the structural and functional attributes of old growth, as well as its associated plant communities and wildlife, both to determine the possible need for treatment and to assess post-treatment progress toward desired conditions. Monitoring can be used to detect conditions (or agents) that threaten existing old growth and also to document indicators of healthy, functioning oldgrowth systems.
\end{abstract}

Key Words: disturbance agents; monitoring; physiological/functional indicators; risk assessment; structural indicators

\section{INTRODUCTION}

Old-growth management goals are based on the ecological, economic, and social expectations associated with specific ownerships and old-growth stands. Certain stand features are especially useful as indicators of old-growth conditions and posttreatment progress toward desired conditions. Choosing which old-growth indicators to monitor depends on management goals and objectives, although time and money are also major constraints in deciding what to measure. Some structural indicators that can be used to assess old-growth conditions are listed in Table 1.

\section{STRUCTURAL INDICATORS}

The popularity of monitoring structural features is due to their close relationship with functions and processes, and their ease of measurement. One general indicator of treatment success in old-growth areas is post-treatment conditions that would allow fire use. Some measures of progress toward oldgrowth goals (e.g., structural) are readily quantifiable after treatment, whereas others are either more subjective (e.g., resiliency to disturbance processes) or require one or more years to respond (e.g., tree regeneration, tree physiological response, understory vegetation, or wildlife populations).

\section{Minimum Structural Requirements}

Structural requirements for old-growth ponderosa pine (Pinus ponderosa var. ponderosa) are presented here as an example of a frequent-fire forest type. The structural requirements presented in Table 2 are less restrictive for most features than the U.S. Department of Agriculture (USDA) Forest Service requirements (Green et al. 1992, Mehl 1992, Hamilton 1993, USDA Forest Service 1993), so that potential old-growth stands can also be identified. Potential old growth includes forest stands (Categories 2 and 3; see article by Fiedler et al. in this issue for definition of these categories) that are likely to develop into old growth in the future if stand vigor is maintained. It is important to identify potential old-growth areas because some existing old-growth stands will inevitably be lost to standreplacing disturbances. 
Table 1. Structural indicators of old growth

\author{
Stand density (e.g., number of trees, basal area, or stand density index) \\ Spatial distribution of old trees (clumped or random) \\ Species composition \\ Live crown ratio \\ Diameter class distribution \\ Age class distribution \\ Age of oldest trees \\ Number of canopy layers \\ Canopy cover \\ Snag density (number of dead trees) \\ Dead and downed logs (number or volume of downed logs) \\ Amount of dead or broken tops/boles
}

\section{Minimum Diameter Requirements}

The minimum structural requirements for old growth listed in Table 2 apply to ponderosa pine stands on dry sites. A minimum diameter of $38 \mathrm{~cm}$, equating to an age of about 125 years, was found to be a reasonable old-growth threshold for dry ponderosa pine forests in eastern Montana (Morgan et al. 2002). As site quality increases (e.g., soil depth and available water increase), minimums for live tree density and diameter also increase. For example, higher-quality sites may have from 25 to 100 old trees per hectare that are at least $50 \mathrm{~cm}$ in diameter.

\section{Minimum Age Requirements}

Stand age has been proposed as a threshold for oldgrowth definition. However, Hunter and White (1997) surveyed the ecological literature in search of step-functions, or sharp changes in forest attributes over a few years, that might provide evidence for stand age as a threshold for old growth, but found none. Although a "litmus" age is difficult to define because of the gradual transition from mature forest to old-growth characteristics, stands with large ponderosa pine trees that pre-date the period from about 1860 to 1880 are commonly considered "old growth." These dates, although arbitrary, approximate the period when EuroAmerican settlement and broad-scale livestock grazing began to fundamentally change the frequent-fire regime that historically shaped drier western forests.

\section{Coarse Woody Debris}

The number of snags and logs and the thickness of the forest floor generally increase as fire frequency decreases. Various accounts of ponderosa pine stand conditions from the late 1800 s and early 1900 s included descriptions of widely spaced trees and few downed logs (Hessburg and Agee 2003). A study by Morgan et al. (2002) also reported few snags and downed logs in old-growth pine stands in eastern Montana. In contrast, Youngblood et al. (2004) reported a considerable volume of coarse woody debris in old-growth ponderosa pine stands in Oregon and California, although this high volume of dead and downed material likely developed after many decades without fire. 
Table 2. Minimum stand structural requirements for old-growth ponderosa pine

\begin{tabular}{ll}
\hline \hline Parameter & Minimum Value \\
\hline Live tree density & $20-25$ trees per ha (tph) \\
Diameter at breast height $(\mathrm{dbh})$ & $38-50 \mathrm{~cm}($ dry sites $) ;>50 \mathrm{~cm}$ (moister sites) \\
Age at breast height & $125-150$ years \\
Number of canopy layers & 1 story, 2 stories, or multi-storied \\
Tree decadence & Not required, but expected if some very old trees are present \\
Snag density & 5 per ha $>25 \mathrm{~cm}$ diameter (desired) \\
Downed logs & Not required, but numbers increase in the absence of fire
\end{tabular}

\section{Old-growth Quality}

Indices of old-growth quality or "old-growthness" (Spies and Franklin 1988) generally rate stands on the premise that old-growth functions increase as numbers of large trees, snags, and downed logs increase. Pfister et al. (2000) point out that one potentially attractive feature of index methods is the flexibility they provide to address the great variation in old-growth conditions. One general problem with index methods is that old-growth attributes are not expressed on a comparable basis. Another shortcoming of indices that comprise numerous attributes is that a stand can rate relatively high in overall index value, yet support few large trees (Pfister et al. 2000). More qualitative indices, derived from public perceptions of aesthetics and spiritual values, can also be developed using survey methods.

\section{PHYSIOLOGICAL/FUNCTIONAL INDICATORS}

Other useful indicators of old-growth status are derived from the physiological condition of the component trees (Table 3). Physiological indicators provide both direct and indirect measures of tree vigor and nutrient status. For example, the availability of soil nutrients, particularly nitrogen, in old-growth stands declines as nutrients increasingly become bound in standing trees and forest floor materials. The carbon:nitrogen ratio increases as organic matter accumulates on the forest floor, thereby decreasing the amount of nitrogen available for growth and reducing tree vigor.

Post-treatment responses in terms of ponderosa pine regeneration and the understory plant community also provide useful benchmarks for evaluating progress toward old-growth goals. These plantbased yardsticks of changed environmental conditions and increased resource availability are natural/ecological indicators of whether treatments had the desired effects.

\section{Tree Vigor Indices}

Monitoring should focus on individual tree characteristics that reflect vigor, such as live crown ratio or foliage color and density, or employ vigor classifications (e.g., Keen 1936, Salman and Bongberg 1942) that reflect growth potential and resistance to bark beetles. Maintaining visual manifestations of vigor increases the likelihood that young trees will survive and develop to become large-tree components of old-growth stands. Increment cores can also reveal slowing radial growth and declining tree vigor caused by stand density levels that are too high relative to a site's available resources. 
Table 3. Physiological/nutritional indicators of old growth

\author{
Forest Descriptors \\ Live crown ratio \\ Foliage color \\ Foliage density/needle length \\ Leaf nitrogen content \\ Pre-dawn leaf water potential \\ Oleoresin exudation pressure \\ Radial growth increment \\ Carbon:nitrogen ratio in forest floor
}

\section{Ponderosa Pine Regeneration}

Regeneration and reasonable juvenile height growth of shade-intolerant species are useful measures of progress toward sustainable old-growth conditions in frequent-fire forest ecosystems. Although regeneration is neither required nor desired throughout the stand, periodic establishment of ponderosa pine regeneration in openings or lowdensity areas created by treatments is one important indicator of treatment success. Presence of pine seedlings alone is not sufficient because small trees must develop rapidly enough to eventually become part of the overstory. Indeed, very slow height growth of shade-intolerant regeneration is a key indicator that treatments did not adequately reduce density (Arno and Fiedler 2005).

\section{Understory Species' Productivity, Composition, and Lifeforms}

Historical old-growth stands had productive understory communities, particularly herbaceous plants. Low biomass productivity of herbaceous species is a characteristic of today's dense, oldgrowth stands. Conversely, significantly increased understory productivity following treatment is a key indicator of progress toward functioning old-growth conditions (Wienk et al. 2004, Moore et al. 2006).
Species composition of the understory community is a prime indicator of a functioning old-growth forest community. Healthy old-growth communities should support high native species diversity and low presence and cover of exotic species, especially invasive exotics. Old-growth pine forests with uninterrupted fire regimes maintain greater native species diversity than old-growth forests from which fire has been excluded (Laughlin et al. 2004). Restoration treatments have been shown to significantly increase native species diversity, although they can also increase exotic species richness and cover, at least over the short term. Exotic species response appears to be an integral, although unwanted, byproduct of restoration for the first 3-5 years following treatment (Dodson and Fiedler 2006). Exotic response appears to be associated with increasing intensity of treatment or multiple treatments (e.g., thinning followed by burning) over a short time period.

Historical old-growth stands in frequent-fire regimes were dominated by forbs and graminoids, with relatively few large shrubs. Today's stands typically exhibit a dense layer or patches of coniferous seedlings and saplings, greater shrub composition, and reduced numbers and cover of native forbs and grasses. Restoration treatments differentially affect each of these lifeforms. Thinning and burning significantly reduce shrubs 
(Griffis et al. 2001) and small conifers, and significantly increase native graminoids (Griffis et al. 2001) and forbs (Laughlin et al. 2004, Wienk et al. 2004). Each of these changes provides a useful benchmark of progress toward more functional and sustainable old-growth conditions.

\section{ASSOCIATED WILDLIFE}

Monitoring wildlife is a useful tool in old-growth management not only because it conveys important information about wildlife populations, but because it indirectly monitors habitat conditions and the effectiveness of old-growth restoration or maintenance treatments. Many animal species that live in fire-dependent western forests respond specifically to some of the attributes that make up old-growth forest stands, such as vertical layering, horizontal patchiness, large living and dead trees, and trees with decay or mistletoe brooms (Spies 1998, Hunter 1999). Some play important roles in forest ecology, and in creating and perpetuating particular forest structures, such as Abert's squirrels dispersing mycorrhizal fungi (States and Gaud 1997), elk foraging on aspen suckers, and songbirds scattering seeds of trees and shrubs.

For these reasons, as well as public interest in wildlife, and federal and state protection of endangered species, monitoring wildlife is a key step in comprehensive management of current or future old-growth forests. However, monitoring wildlife is often difficult, time consuming, and expensive. Managers need to carefully weigh decisions about which species to monitor and for how long as they plan and implement old-growth treatments.

\section{Choosing Species to Monitor}

Because it is infeasible to monitor all or most of the species that live in association with a particular tract of forest, managers generally choose a few target species that serve as indicators for habitat conditions. For species with special legal status, such as the Mexican spotted owl (Strix occidentalis lucida), monitoring may be mandated. Such indicator species need to be chosen carefully. They generally should be species that are relatively easy to locate and census. Birds are often chosen as indicators precisely for this reason. It is vitally important to monitor species that truly rely on old- growth conditions. In some southwestern forests, for example, both Mexican spotted owls and great horned owls (Bubo virginianus) may be present in old-growth stands, yet only the former is believed to rely primarily on old-growth conditions. Therefore, it is the species most likely to provide credible information about the success of restoration treatments and their effects on wildlife.

One promising approach is to identify a suite of species that represents all the species expected to be present in a particular ecosystem, which Lambeck (1997) has labeled a "restoration assemblage." In the case of treatments aimed at preserving or restoring old-growth structure, for example, these might be species that use different parts of an oldgrowth ecosystem - tree canopies, snags, exfoliating bark, downed woody debris, or the herbaceous understory. Raphael et al. (2001) used this approach and identified the pygmy nuthatch (Sitta pygmaea) as an indicator for old-growth conditions in the interior Columbia River Basin because it uses large snags for nesting and live trees for foraging. Whatever method is employed, it is vital that indicator species be carefully selected because it is easy to choose species that do not represent a full range of ecological uses (Block et al. 2001). More details on selecting species to monitor and devising monitoring protocols can be found in Thompson et al. (1998) and Morrison (2002).

\section{Spatial Scale}

In choosing species to monitor, it is essential to consider the scale of the areas treated. Monitoring can only document treatment effects on wildlife species if the treatments are large enough to truly affect habitat usage. In Arizona, for example, a set of experimental blocks was established outside Flagstaff to monitor the effects of various restoration treatments in ponderosa pine forest. The blocks were only 14 ha in size, which was too small to monitor effects on songbirds, deer, raptors, and many other species with home ranges as large or larger than the blocks (Fulé 2003). However, the blocks are large enough to monitor butterfly activity and some other species, such as small mammals (Chambers and Germaine 2003).

Monitoring must also consider the placement of treatment areas within a larger landscape context. Variables affecting the larger landscape, such as extreme weather events, drought, climate shifts, and 
large-scale management decisions, can affect wildlife populations and overwhelm the effect of habitat changes at the scale of a single home range.

\section{Temporal Scale}

The dimension of time is critical because it allows researchers to begin to understand trends and population dynamics, rather than merely acquiring a snapshot of wildlife populations at a single point in time. For example, Battin and Sisk (2003) showed that some bird species remain in altered habitats created by treatments intended to enhance oldgrowth conditions, but that these habitats sometimes represent population sinks that do not bolster overall populations.

Optimally, monitoring protocols would incorporate specific measures of population dynamics, such as reproductive success. However, it is often more feasible to use relative population change as a partial surrogate for more precise measures of population change. In the case of treatments intended to conserve or develop old-growth conditions, it is particularly important to measure both short- and long-term wildlife responses to treatment. For example, a thinning treatment in an area that currently lacks old-growth structure may initially remove much tree biomass and disturb soils, resulting in a decline in wildlife abundance or diversity. After a few years of regrowth, however, the understory may show greater diversity and richness of plant species than before treatment, resulting in a concomitant increase in wildlife activity. After a few decades, increased tree growth may translate into incipient old-growth conditions and an increase in associated wildlife species. Monitoring protocols that incorporate measurements at varied times after treatment are needed to detect such changes.

\section{MONITORING DISTURBANCE PROCESSES AND ASSESSING RISK}

Perpetuating old-growth ponderosa pine stands requires maintaining resistance to disturbance agents (insects, disease, and wildfire) that can cause unprecedented levels of damage. Although each of these agents is an integral part of a healthy oldgrowth ecosystem, historically they have operated to damage or kill trees at the tree or clump level, not the stand level. Today, that is no longer the case. However, a number of hazard rating systems can be used to assess relative risk from these agents. For example, some of the individual-tree characteristics listed in Table 2 can be used to develop stand-level hazard ratings for bark beetles (Dendroctonus spp.), dwarf mistletoe (Arceuthobium spp.), and wildfire hazard.

\section{Bark Beetle Hazard}

Bark beetle hazard increases as stand density and moisture stress increase, and as oleoresin exudation pressure decreases (Vité 1961). Two tree vigorbeetle susceptibility classifications have been developed for ponderosa pine (Keen 1936, Salman and Bongberg 1942). These classifications are most useful when bark beetles are at endemic rather than epidemic levels, and for rating bark beetle hazard in the Inland Northwest/California variety of ponderosa pine.

\section{Dwarf Mistletoe}

Dwarf mistletoe is a parasitic plant that grows on trees and extracts resources that would otherwise be used for tree growth. Hawksworth (1979) developed a mistletoe rating system, ranging from class 1 (minor infection, with little effect on tree physiological function) to class 6 (severe infection, likely to result in tree mortality). Although mistletoe infection is undesirable at any level, it is a problem that must be endured in Category 1 old-growth areas, regardless of severity. In contrast, because of the limited resources available for managing stands for future old growth, treatments should only be considered in Category 2 areas if they are uninfected or have light (class 1 or 2) dwarf mistletoe ratings. Virtually no level of infection should be tolerated in Category 3 stands because of the long period (decades to centuries) that will be required for such stands to develop old-growth characteristics, even with thoughtful management.

\section{Wildfire Hazard}

Wildfire hazard can be measured at the landscape level or the stand level, using various readily available models. Fire Regime Condition Class ( http://www.frcc.gov/) is a tool that assesses the degree of departure from the historical natural fire 
regime and reflects changes in vegetation, fuels, and associated disturbances at a landscape scale. Models, such as the Fuels Management Analyst Plus (Fire Program Solutions LLC 2005; http://www.fir eps.com/software/ug fma.pdf) and the Fire and Fuels Extension to the Forest Vegetation Simulator (Beukema et al. 1997; http://www.treesearch.fs.fed. us/pubs/5593), can provide stand-level assessments of hazard. These models use various individual tree or stand-level measurements as inputs to calculate wildfire hazard rating in terms of fire behavior potential, crown fire potential, and available fuel potential. Wildfire hazard generally increases as surface fuels, canopy bulk density, and ladder fuels increase, and as height-to-live crown decreases (Agee and Skinner 2005).

\section{CONCLUSION}

Monitoring is an essential component of projects designed to develop or maintain old-growth characteristics. Maturing and old-growth forest conditions, and the kinds of treatments that may be needed to modify or maintain them, vary greatly at local and regional scales. Through monitoring, valuable information can be obtained for refining treatment prescriptions to better match specific forest conditions, sites, and landowner objectives.

Monitoring is an imperfect science, especially in relation to old growth or incipient old-growth forests. Resources will never be sufficient to monitor everything that managers or researchers would like to know. Nor can we know now some of the important questions of the future-particularly given a changing climate. For these reasons, it is vital to design monitoring protocols that are both broad (measure a variety of indicators) and flexible (open to modification over time). Experience and knowledge gained through monitoring can help ensure that today's well-intentioned treatments will ultimately achieve their long-term goals.

Responses to this article can be read online at: http://www.ecologyandsociety.org/vol12/iss2/art22/responses/

\section{LITERATURE CITED}

Agee, J. K., and C. N. Skinner. 2005. Basic principles of forest fuel reduction treatments. Forest Ecology and Management 211:83-96.

Arno, S. F., and C. E. Fiedler. 2005. Mimicking nature's fire: restoring fire-proneforests in the West. Island Press, Washington, D.C., USA.

Battin, J., and T. D. Sisk. 2003. Assessing landscape-level influences of forest restoration on animal populations. Pages 175-190 in P. Friederici, editor. Ecological restoration of southwestern ponderosa pine forests. Island Press, Washington, D.C., USA.

Beukema, S. J., J. A. Greenough, D. C. E. Robinson, W. A. Kurz, E. D. Reinhardt, N. L. Crookston, J. K. Brown, C. C. Hardy, and A. R. Stage. 1997. An introduction to the fire and fuels extension to FVS. Pages 191-195 in R. Teck, M. Moeur, and J. Adams, editors. Proceedings of the forest vegetation simulator conference. U.S. Forest Service General Technical Report INT-373.

Block, W. M., A. B. Franklin, J. P. Ward, Jr., J. L. Ganey, and G. C. White. 2001. Design and implementation of monitoring studies to evaluate the success of ecological restoration on wildlife. Restoration Ecology 9:293-303.

Chambers, C. L., and S. S. Germaine. 2003. Vertebrates. Pages 268-285 in P. Friederici, editor. Ecological restoration of southwestern ponderosa pine forests. Island Press, Washington, D.C., USA.

Dodson, E. K., and C. E. Fiedler. 2006. Impacts of restoration treatments on alien plant invasion in Pinus ponderosa forests, Montana, USA. Journal of Applied Ecology 43:887-897.

Fire Program Solutions, LLC. 2005. Fuels Management Analyst Plus v 1.2.20. Fire Program Solutions, LLC, Estacada, Oregon, USA.

Fulé, P. Z. 2003. Monitoring. Pages 402-416 in P. Friederici, editor. Ecological restoration of southwestern ponderosa pine forests. Island Press, Washington, D.C., USA.

Green, P., J. Joy, D. Sirucek, W. Hann, A. Zack, and B. Naumann. 1992. Old-growth forest types of the northern region. U.S. Forest Service, Northern 
Region R1 SES 4/92.

Griffis, K. L., J. A. Crawford, M. R. Wagner, and W. H. Moir. 2001. Understory response to management treatments in northern Arizona ponderosa pine forests. Forest Ecology and Management 146:239-245.

Hamilton, R. G., compiler. 1993. Characteristics of old-growth forests in the Intermountain Region. Unpublished report on file at USDA Forest Service, Intermountain Region, Ogden, Utah, USA.

Hawksworth, F. G. 1979. The 6-class dwarf mistletoe rating system. U.S. Forest Service General Technical Report RM-48.

Hessburg, P. F., and J. K. Agee. 2003. An environmental narrative of Inland Northwest United States forests, 1800-2000. Forest Ecology and Management 178:23-59.

Hunter, M. L., Jr., editor. 1999. Maintaining biodiversity in forest ecosystems. Cambridge University Press, New York, New York, USA.

Hunter, M. L. Jr., and A. S. White. 1997. Ecological thresholds and the definition of oldgrowth forest stands. Natural Areas Journal 17:292-296.

Keen, F. 1936. Relative susceptibility of ponderosa pine to bark-beetle attack. Journal of Forestry 34:919-927.

Lambeck, R. J. 1997. Focal species: a multi-species umbrella for nature conservation. Conservation Biology 11:849-856.

Laughlin, D. C., J. D. Bakker, M. T. Stoddard, M. L. Daniels, J. D. Springer, C. M. Gildar, A. M. Green, and W. W. Covington. 2004. Toward reference conditions: wildfire effects on flora in an old-growth ponderosa pine forest. Forest Ecology and Management 199:137-152.

Mehl, M. S. 1992. Old-growth descriptions for the major forest cover types in the Rocky Mountain Region. In M. R. Kaufmann, W. H. Moir, and R. L. Bassett, technical coordinators. Old-growth forests in the Southwest and Rocky Mountain regions: Proceedings of a workshop. U.S. Forest Service General Technical Report RM-213.
Moore, M. M., C. A. Casey, J. D. Bakker, J. D. Springer, P. Z. Fulé, W. W. Covington, and D. C. Laughlin. 2006. Herbaceous vegetation responses (1992-2004) to restoration treatments in a ponderosa pine forest. Rangeland Ecology and Management 59:135-144.

Morgan, T. A., C. E. Fiedler, and C. W. Woodall. 2002. Characteristics of dry site old-growth ponderosa pine in the Bull Mountains of Montana, USA. Natural Areas Journal 22:11-19.

Morrison, M. L. 2002. Wildlife restoration: techniques for habitat analysis and animal monitoring. Island Press, Washington, D.C., USA.

Pfister, R. D., W. L. Baker, C. E. Fiedler, and J. W. Thomas. 2000. Contract review of old-growth management on school trust lands: supplemental biodiversity guidance. Report to the Montana Department of Natural Resources and Conservation.

Raphael, M. G., M. J. Wisdom, M. M. Rowland, R. S. Holthausen, B. C. Wales, B. G. Marcot, and T. D. Rich. 2001. Status and trends of habitats of terrestrial vertebrates in relation to land management in the interior Columbia River Basin. Forest Ecology and Management 153:63-88.

Salman, K. A., and J. W. Bongberg. 1942. Logging high-risk trees to control insects in the pine stands of northeastern California. Journal of Forestry 40:533-539.

Spies, T. A. 1998. Forest structure: a key to the ecosystem. Northwest Science 72:34-39.

Spies, T. A., and J. F. Franklin. 1988. The diversity and maintenance of old-growth forests. Pages 296314 in R. Szaro and D. Johnston, editors. Biodiversity on managed landscapes. Oxford University Press, New York, New York, USA.

States, J. S., and W. S. Gaud. 1997. Ecology of hypogeous fungi associated with ponderosa pine. I. Patterns of distribution and sporocarp production in some Arizona forests. Mycologia 89:712-721.

Thompson, W. L., G. C. White, and C. Gowan. 1998. Monitoring vertebrate populations. Academic Press, San Diego, California, USA.

U.S. Department of Agriculture. 1993. Region 6 interim old growth definition for Douglas-fir series, 
grand fir/white fir series, interior Douglas-fir series, lodgepole pine series, Pacific silver fir series, ponderosa pine series, Port Orford-cedar and tanoak (redwood) series, subalpine fir series, and western hemlock series. USDA Forest Service, Pacific Northwest Region, Portland, Oregon, USA.

Vité, J. 1961. The influence of water supply on oleoresin exudation pressure and resistance to bark beetle attack in Pinus ponderosa. Contribution Boyce Thompson Institute 21:37-66.

Wienk, C. L., C. H. Sieg, and G. R. McPherson. 2004. Evaluating the role of cutting treatments, fire and soil seed banks in an experimental framework in ponderosa pine forests of the Black Hills, South Dakota. Forest Ecology and Management 192:375393.

Youngblood, A., T. Max, and K. Coe. 2004. Stand structure in eastside old-growth ponderosa pine forests of Oregon and northern California. Forest Ecology and Management 199:191-217. 